\title{
PRÁXIS FEMINISTA: a presença de Heleieth Saffioti nos estudos e nas lutas no Brasil
}

\author{
Tita Carneiro* \\ Maíra Kubík Mano* *
}

\begin{abstract}
Heleieth Saffioti foi uma intelectual que durante toda sua trajetória manteve uma postura apoiada sobre a práxis feminista: se, por um lado, suas contribuições teóricas serviram de inspiração e elucidação para a compreensão das desigualdades que impactam, em especial, as mulheres brasileiras; por outro, as pautas feministas e dos movimentos de mulheres foram seus objetos de estudo e alimentaram sua obra. Podemos dizer que Saffioti estabeleceu, em sua produção, uma relação simbiótica própria do campo teórico em que se referencia e procurou, por meio dela, buscar sínteses para transformar a realidade. Neste artigo, refletimos sobre suas contribuições para os estudos e as lutas feministas no Brasil, revisitando seu livro pioneiro A mulher na sociedade de classes no momento de seu lançamento e também buscando compreender de que forma seu instrumental teórico colaborou e colabora para analisarmos e enfrentarmos as hierarquias sociais.

Palavras-chave: Academia. Teoria feminista. Conscientização. Práxis.
\end{abstract}

\section{INTRODUÇÃO}

No livro A mulher na sociedade de classes (1969), Heleieth Iara Bongiovani Saffioti se lança à construção de uma teoria que considera os fatores sexo e raça, ou ainda as desigualdades relacionadas a estas duas dimensões, juntamente às classes sociais no desenrolar de nossa história. A autora faz isto construindo uma teoria sociológica que incorpora o conhecimento desenvolvido em países capitalistas centrais, dentre eles as teorias feministas mais recentes à época. No entanto, critica fortemente a sua incorporação de modo irrestrito como se fosse uma mera aplicação. Dentre os vários debates travados na tese, investiga a forma como surgem e se desenvolvem os movimentos femininos e feministas no Brasil, contribuindo assim para o avanço dos mesmos, tanto no sentido político quanto analítico.

* Universidade Federal da Bahia (UFBA). Núcleo de Estudos Interdisciplinares sobre a Mulher (NEIM).

Estrada de São Lázaro, 197. Federação. Salvador - Bahia Brasil. titacarneiro@yahoo.com.br

https://orcid.org/0000-0001-9322-2865

** Universidade Federal da Bahia (UFBA). Núcleo de Estudos Interdisciplinares sobre a Mulher (NEIM).

Estrada de São Lázaro, 197. Federação. Salvador - Bahia Brasil.maira.kubik@ufba.br

https://orcid.org/0000-0002-4201-5636
Neste artigo, buscaremos refletir sobre a importância do lançamento e da circulação desta obra à luz da práxis feminista, compreendendo que a elaboração teórica ali desenvolvida trouxe aportes não apenas para o desenvolvimento do campo de estudos de gênero e feminismo dentro da academia brasileira, como também contribuiu para a elaboração dos movimentos sociais, que têm nessa obra uma importante referência. Em um primeiro momento, traremos o conceito de práxis feminista. Em seguida, nos aproximaremos de Saffioti e sua obra para, finalmente, falar sobre sua herança intelectual.

\section{SITUACIONALIDADE DA AUTORA}

Ao abordar a importância da obra de Saffioti a partir da perspectiva da práxis, nossa escolha consiste, obviamente, em nos afiliarmos ao mesmo campo teórico no qual a autora transita: o materialismo histórico-dialético. Como nos explica Leandro Konder:

A práxis é a atividade concreta pela qual os sujeitos humanos se afirmam no mundo, modificando a re- 
alidade objetiva e, para poderem alterá-la, transformando-se a si mesmos. É a ação que, para se aprofundar de maneira mais consequente, precisa da reflexão, do autoquestionamento, da teoria; é esta que remete à ação, que enfrenta o desafio de verificar seus acertos e desacertos, cotejando-os com a prática (Konder, 1992, p. 115).

Portanto, há uma interligação e uma interpendência entre práxis e teoria (Konder, 1992, p. 116). As epistemologias feministas beberam da fonte marxista para refletir sobre a importância da situacionalidade do sujeito para a elaboração do pensamento. Como coloca Sandra Harding

A história intelectual da teoria feminista do standpoint é convencionalmente traçada das reflexões de Hegel sobre o que ficou conhecido como a relação senhor-escravo do ponto de vista do escravo versus aquele da vida do mestre até o modo com que Marx, Engels e Lukacs subsequentemente desenvolveram esse insight para o "ponto de vista do proletariado", a partir do qual produziram as teorias marxistas sobre como a sociedade de classes opera (Harding, 1996, p. 54).

Assim, a partir dos anos 1970, muitas pensadoras feministas começaram a refletir sobre como "a análise marxista poderia ser transformada para explicar de que forma a relação estrutural entre mulheres e homens tinha consequências para a produção do conhecimento" (Harding, 1996, p. 54). Entre os pontos mais debatidos então, estava a importância das histórias de vida e experiências pessoais para a จิ formulação de ideias. Por um lado, as feminisஸ tas reivindicavam a importância da perspec¿ै tiva daqueles e daquelas cujas vidas haviam sido marginalizadas para o desenvolvimento ㄱ da pesquisa científica. Por outro, rejeitavam ¿. o risco de uma elaboração etnocêntrica: era ભ preciso não cair em um automatismo onde de$\vec{t}$ terminado corpos produziriam determinadas reflexões - um exemplo usado com frequência era o fato de Karl Marx e Friedrich Engels não terem origem no proletariado e, mesmo assim, terem dedicado toda sua produção teórica à emancipação da classe trabalhadora.
Contudo, não existe uma contradição nessas duas abordagens, pelo contrário, pode-se, a partir delas, enriquecer a produção do conhecimento. Assim, ao pensar sobre a relação entre o singular e o universal, Patricia Hill Collins afirma que

[ ] embora o fato de se viver a vida como mulher negra possa produzir certas visões compartilhadas, a variedade de classe, região, idade e orientação sexual que moldam as vidas individuais de mulheres negras tem resultado em diferentes expressões desses temas comuns. Portanto, temas universais que são incluídos nos pontos de vista de mulheres negras podem ser experimentados e expressos de forma distinta por grupos diferentes de mulheres afro-americanas (Hill Collins, 2016, p. 120).

Mesmo não havendo uma transposição automática para os feminismos, assim como para o marxismo, a situacionalidade do sujeito é fundamental, é a visão parcial, no sentido de enxergar apenas uma parcela, mas também de parcialidade, ao escolher conscientemente posicionar-se (Juteau, 1981). Desta forma, faz diferença pensarmos inicialmente sobre a origem de Saffioti e em sua trajetória: sua mãe era costureira e seu pai, pedreiro. Essa origem na classe trabalhadora impactaria definitivamente sua obra. Ela lembrava que

\footnotetext{
Minha mãe não chegou nem a sequer à condição de operária. Ela tinha máquina de costura e trabalhava por conta própria, o que é pior do que ter uma carteira assinada. E meu pai, nas mesmas circunstâncias, quando havia trabalho, se trabalhava, quando não havia, não havia o que se fazer porque época de chuva não se constrói. Então, foi uma infância muito difícil do ponto financeiro, mas, por outro lado, me trouxe muitas alegrias (Saffioti apud Méndez, 1998, p. 275).
}

Após enfrentar dificuldades para conseguir estudar e se mudar algumas vezes de cidades no interior de São Paulo, ficando inclusive longe de sua família, Saffioti chega a São Paulo e é aprovada para estudar no curso noturno do tradicional colégio Caetano de Campos, na Praça da República, local que, posteriormente, seria sua última moradia. "Em suas memórias 
encontramos as experiências de falta de liberdade em função do duplo 'destino' de classe e de gênero”, nos conta Renata Gonçalves (2011, p. 5): aos 13-14 anos, "por ser a sobrinha sem posses, filha da costureira e do pedreiro, fez as vezes de Gata Borralheira, responsável pelo serviço doméstico" (Pompeu, 2007, p. 68). "Fazia todo o trabalho da casa, estudava no período noturno e voltava sozinha para casa após a meia noite" (Gonçalves, 2011, p. 5).

De lá, partiu para a Escola Normal. Ela contava que

[ ] havia épocas em que eu tinha três empregos, um pela manhã, um à tarde, entre o da tarde do qual eu saía às 17 horas para entrar depois na escola às 19 horas, eu dava aulas particulares de português. Eram três empregos, e eu não podia ter a pretensão de ser a primeira colocada com todas essas atividades. Havia, depois da Escola Normal, um ano de aperfeiçoamento de professores, só pela manhã, não havia à noite. Então, eu arranjei um emprego à tarde e outro à noite para poder estudar de manhã (Saffioti apud Méndez, 1998, p. 279).

Seguindo o percurso acadêmico, Saffioti foi aprovada no vestibular de Ciências Sociais da Universidade de São Paulo (USP). "Prestei o vestibular - sem cursinho, sem nada - para Ciências Sociais na USP. Naquela época, a coisa era duríssima. Primeiro, não haviam livros em português. (...) espanhol, por exemplo, eu aprendi "na marra”, recordava (Saffioti apud Méndez, 1998, p. 280). Conforme avançou na carreira, abraçou o marxismo e, em sua tese de livre docência, foi orientada por Florestan Fernandes. A esse respeito, ela comenta que "seu livro [A mulher na sociedade de classes] era escancaradamente marxista" (Saffioti apud Méndez, 1998, p. 285). Após uma banca extremamente rigorosa ela foi aprovada.

Antonio Cândido, no prefácio que fez para esta obra, relata a proximidade entre Saffioti e Florestan ao dizer que ambos "denotam pertinácia, destemor ante a massa de dados, disposição de levar a análise ao cabo das idéias" (Candido, 1979, p. 9). A tese, segundo Cândido, enlaça “a preocupação teórica ao senso constante da realidade presente" (Ibid, p.9). Florestan, assim como Saffioti, também tinha uma origem nas camadas populares: começou a trabalhar aos seis anos como ajudante de barbeiro e engraxate. Passou por diversos outros lugares, como uma marcenaria, uma alfaiataria, uma padaria e um restaurante antes de ingressar, como estudante, na Faculdade de Filosofia, Letras e Ciências Humanas da USP (Xavier, s/d).

Dessa forma, a partir das proposições que as epistemologias feministas nos oferecem, afirmamos que as experiências de vida têm influência na aproximação aos problemas, às questões e hipóteses formuladas, às metodologias escolhidas, no tratamento dos dados etc. No caso de Saffioti, elas podem explicar parcialmente as motivações para esse fazer científico, ao comentar sobre a implicação do sujeito nas Ciências Humanas na introdução de A mulher na sociedade de classes:

Assim, é possível não apenas desmistificar, mas ainda questionar a capacidade instrumental das ciências humanas afirmadoras do status quo capitalista para solucionar problemas sociais gerados por essa ordem, sobretudo, quando manipulada pelos centros decisórios das sociedades competitivas, e a viabilidade do processo de incorporação uniforme dos conhecimentos científicos por uma população dividida em classes sociais. Uma vez que todo conhecimento que um ser tem de si mesmo não é ciência, mas consciência, não cabe falar-se de uma ciência social conservadora e de uma ciência social negadora da ordem social competitiva, mas de uma consciência burguesa e de uma consciência proletária, pois todo pensamento se liga intimamente à ação (Saffioti, 1976, p. 16).

Nas décadas que se seguiram à publicação do livro inaugural, suas análises caminharam pelos diferentes aspectos da opressão capitalista e patriarcal, tais como o emprego doméstico e a violência e, justamente por isso, contribuíram para inspirar os movimentos de mulheres. É na junção entre feminismo e marxismo que encontramos seu pensamento. Sem cair na cilada de atestar ou não sua militância, podemos dizer que Saffioti permaneceu mu- 
niciando gerações para buscar saídas para sua principal preocupação, que segue atual e que pode ser resumida em uma nota à segunda edição de A mulher na sociedade de classes: "até o momento, portanto, as vitórias feministas não extrapolaram os limites impostos pelo modo de produção capitalista" (Saffioti, 1979, p. 7).

\section{CRÍTICA AO FEMINISMO BURGUÊS E À “IMPORTAÇÃO” DO FEMINIS- MO EUROPEU E ESTADUNIDENSE}

Em A mulher na sociedade de classes, Saffioti antevê dilemas relacionados aos estudos sobre as mulheres, assim como as manifestações feministas, no que se refere à nossa experiência brasileira, compreendendo a relação dialética e, por vezes, contraditória entre um e outro. Sua crítica é muito sagaz à forma como são "importados" os feminismos de outros contextos na primeira metade do século $\mathrm{XX}$ e transportados para a nossa realidade. $\mathrm{O}$ que ela critica não é o fato de que aqui se conhecesse o que estava acontecendo nos países de capitalismo central, mas antes a tentativa de copiar ou de encaixar conceitos e modos de agir em nossa realidade. Saffioti, assim como Florestan, foi uma grande entusiasta da capacidade de elaborarmos sobre a nossa própria experiência, o que nem de longe se aproximou de um rechaço ao estrangeiro ou diferente.

Nessa perspectiva, em um artigo escrito em 1999, Saffioti comenta por que não utiliza a abordagem de Simone de Beauvoir em $A$ mulher na sociedade de classes - a francesa é citada apenas três vezes ao longo do livro:

\footnotetext{
Cabe-me, contudo, apontar uma questão de ordem metodológica para explicar uma resistência emocional minha para usar Beauvoir. Minha adesão ao materialismo histórico tornou-me crítica de uma visão que considerei excessivamente culturalista. No início da década de 1960, o conceito de cultura envolvia crenças, normas, valores, mas não a práxis, fenômeno que tenho como muito importante na construção de homens e mulheres e suas relações. Como Beauvoir, ainda que utilizando Engels, critica
}

o materialismo histórico, situando-se na ontologia fenomenológica de O Ser e o Nada, julguei-me capaz - quanta pretensão! - de fazer-lhe o contraponto, partindo para uma análise centrada em relações econômicas, estrutura de poder e descompasso entre o material e o ideológico, então chamado de infra-estrutura e superestrutura (Saffioti, 1999, p. 162).

Aqui, além de trazer a importância de uma abordagem própria, singular, Saffioti também revela a centralidade da práxis em sua análise. O trabalho é, para ela, a categoria sociológica chave e é nas relações de produção que encontramos não só a desigualdade de classe social, como também de sexo e raça termos utilizados por ela (Saffioti, 1976, p. 32). Ao falar sobre como seu interesse também não era semelhante ao da filósofa, de uma formulação universal - criticada, aliás, por ela - acentua o interesse de se debruçar sobre realidades específicas: da Europa, dos Estados Unidos e do Brasil. Para tanto, na parte I, "Mulher e capitalismo”, no subitem "A ‘solução' feminista”, a autora apresenta algumas passagens dos movimentos de mulheres no contexto europeu e nos Estados Unidos. Curioso notar que Saffioti mantém a palavra "solução" entre aspas, o que já dá indícios dos limites nas disputas travadas pelo direito ao voto e pela igualdade na educação e no emprego ao final do século XIX e início do século XX, pelo que ela denominou de práxis feminista pequeno-burguesa, que não tinha no horizonte uma transformação estrutural da sociedade. Apenas para citar um trecho, ela afirma

\footnotetext{
Como o conteúdo revolucionário da práxis feminista pequeno-burguesa é dado pelas aspirações de ascensão social alimentadas sobretudo pelos estratos inferiores das camadas intermediárias da sociedade de classes, num esforço de expansão estrutural do sistema, não chega a pôr em xeque os fundamentos do status quo [...](Saffioti, 1976, p. 131).
}

Também não poupa críticas às operárias americanas, as quais, na sua perspectiva, foram incapazes de enfrentar o racismo: "porque as americanas nunca se propuseram a resolver o problema do negro e sim tão somente o do es- 
cravo seriam, mais tarde, presas de sua própria estreiteza de visão" (ibidem, p. 123). Aqui, Saffioti apresenta um problema que perpassaria não apenas esse livro, mas toda a sua obra: a impossibilidade de pensar a emancipação humana dissociada da superação das desigualdades de classe social, sexo (e depois gênero) e raça. A respeito desse período histórico - muito bem analisado aliás por Ângela Davis em $\mathrm{Mu}$ Iheres, Raça e Classe [2016 (1981)], que aponta as confluências e contradições entre as lutas feminista e abolicionista - Saffioti afirma que as operárias resolveram seus problemas "por dentro do sistema", dando-lhe "nova força e vigor":

Para as operárias, porém, a questão não se resumia na obtenção das capacidades civis e políticas e no direito à instrução. Para quem trabalha até 10 horas da noite, recebendo ínfimos salários, a problemática feminina assume outros contornos. Eis por que elas enfrentam o frio glacial e suportam a fome para manter os piquetes de greve. Do mesmo modo que as operárias francesas, foram elas acossadas e maltratadas pela polícia. Suas aspirações, contudo, representavam um problema menor para os dirigentes da nação do que as das francesas para seu governo. Por isso acabam por se resolver no e pelo sistema, dando-lhe nova força e vigor (Saffioti, 1976, p. 131).

Com o mesmo rigor, a autora analisa as diferentes posições dos comunistas e socialistas a respeito do sufrágio universal. Detendo-se mais sobre a realidade alemã, Saffioti traz como exemplo negativo a rejeição à proposta de Auguste Bebel de defender o voto feminino pela maioria dos integrantes do Partido Social-Democrata alemão. Para ela,

Se, de uma parte, a posição puramente feminista é, em si própria, contraditória, de outra, a posição do partido socialista alemão revelava uma deformação pequeno-burguesa. Como a exploração dos recursos oferecidos pelas sociedades de classes para a solução dos problemas por ela gerados pode operar, meramente, como uma etapa de uma luta mais ampla, cujo objetivo seja a substituição de uma estrutura social por outra, a atitude assumida pelo partido em questão se mostra negativista e improdutiva (Ibidem, p. 136).

Ainda assim, há trechos emocionantes, que deixam transparecer nas suas páginas o quanto as questões ali colocadas mobilizavam a autora:

De modo algum, todavia, o feminismo pode ser acusado de ter apresentado a mulher emancipada como um ser racional e carente de vida emocional. Mary Wollstonecraft, Anglina Grimké, Ernestine Rose, Margaret Fuller, Elizabeth Cady Stanton, Julia Ward Howe, Margaret Sanger e tantas outras feministas foram capazes de amar, foram amadas e mães dentro ou fora do casamento legal. É certo que algumas se recusaram a ratificar legalmente suas uniões conjugais. Não o fizeram, entretanto, por uma incapacidade de amar em virtude de terem se tornado seres exclusivamente racionais. Sua atitude deve antes ser encarada como um protesto à submissão da mulher ao homem, imposta pelas leis que regiam, e em alguns países ainda regem, a sociedade conjugal. Quando se luta pela mudança das leis e dos costumes, é pondo-se em prática os padrões que se pretendem instituir que mais vigorosamente se formulam protestos contra a ordem social vigente (Saffioti, 1976, p. 124).

Sabe-se que nos países de capitalismo periférico, como o nosso caso brasileiro, importamos as macro teorias dos países centrais, sejam elas de cunho contestatório ou conservador. No que se refere ao feminismo enquanto movimento político e teórico, dois principais países aos quais nos referenciamos foram a França e os Estados Unidos. Esta importação se fez relevante "no que tange tanto aos movimentos reformistas quanto aos revolucionários" (Saffioti, 2013, p. 356). Pode ser percebida como sendo uma das expressões deste fenômeno o fato de que as preocupações mais pulsantes do movimento feminista brasileiro por algum tempo se relacionavam à questão do trabalho das mulheres, mas no entanto pelo “[...] espírito da época, porém, se fazia necessário encetar a luta organizada a favor do voto feminino" (Saffioti, 2013, p. 292).

Na parte II do mesmo livro, Saffioti destaca, por exemplo, que as manifestações feministas tiveram início no Brasil após a visita de Bertha Lutz a Londres. De volta ao Brasil, já licenciada em Ciências pela Faculdade de Ciências da Universidade de Paris, em 1918, "Bertha Lutz transforma-se na primeira pregadora, 
através da imprensa e da tribuna, da emancipação da mulher" (Ibidem, p. 290). Abria-se, para ela, um lastro entre a realidade nacional e as reivindicações feministas. Tal descompasso fica bastante evidente quando ela analisa as discussões entre Lutz e Carlota Pereira de Queiroz no Congresso Nacional durante o processo de criação do Departamento Nacional da Mulher. Embora com posições distintas, nenhuma das duas deputadas tinha uma postura que vislumbrasse também a transformação da sociedade de classes. Segundo Saffioti, Carlota Pereira de Queiroz

[ ] não visava orientar os elementos femininos de modo a tomá-los economicamente independentes. Neste sentido, seu pensamento parece desenvolver-se conforme a postura dos que pertencem a «famílias tradicionais», admitindo a ascensão social e equiparação ao homem, da mulher de camada dominante, mas vendo na mulher de camada subprivilegiada um ser que, por incapaz de progredir autonomamente, carece da proteção do Estado. Superada a questão do sufrágio feminino, cuja solução parece apreciar, coloca-se Carlota P. de Queiroz numa linha de conduta totalmente consentânea com a divisão da sociedade em classes sociais e com a conservação dos privilégios de que goza a classe dominante (Saffioti, 1976, p. 306).

Já Bertha Lutz foi identificada como reformista cujos ideais estão associados às camadas médias:

Toda sua ação se desenrola no sentido de obter uma expansão da estrutura capitalista no Brasil, de modo a se abrirem novas vias à emancipação econômica da mulher, através do desempenho, por parte do Estado, de funções que o caracterizariam como o Estado do Bem-estar social. As incongruências de seu pensamento resultam de não assumir ela uma postura crítica em relação à estrutura da sociedade competitiva. Por isso não conseguiu estruturar "um núcleo constitucional de organização administrativa dentro do qual possa (a mulher) proceder ao aperfeiçoamento dos fatores humanos e sociais que se congregam em torno da célula mater da sociedade: o Lar", sem promover, simultaneamente, a segregação sexual. Embora não se insurgisse contra a divisão da sociedade em classes sociais, não pretendia conservar, tal como existia, a estrutura social brasileira (Saffioti, 1976, p. 308).
Em um artigo publicado após o falecimento de Saffioti, Céli Regina Pinto a compara com Bertha Lutz ao classificá-las como feministas "bem-comportadas", que encontraram cada qual a seu modo as formas de estabelecer diálogos e cooperação. "Nos dois casos, os posicionamentos, ainda que não fossem entusiasticamente acolhidos, encontravam espaços para se exprimirem com legitimidade", analisa Pinto (2014, p. 331). Para Saffioti, mulheres de setores médios brasileiros incorporam feminismos dos países centrais a partir de uma perspectiva construída no contexto do Bem-Estar Social europeu e estadunidense, de incorporação das mulheres ao mercado de trabalho, sendo visto com grande entusiasmo e como uma possível solução para se alcançar a libertação das mulheres, como se a desigualdade entre os sexos fosse deixar de existir. A sua tese é de grande ousadia, pois, ao mesmo tempo critica as teorias sociológicas que afirmavam tal caminho para as mulheres brasileiras assim como critica os feminismos que incorporam tais ideias.

Deste ângulo, o feminismo pequeno-burguês não é, na verdade, um feminismo. Representa ao contrário, uma força de consolidação da sociedade de classes na medida em que permite a esta assumir uma aparência que melhor dissimule suas contradições internas. A conclusão a que esta constatação leva não pode ser outra senão a de que o feminismo é uma posição falsa se considerada como perspectiva autônoma. Na verdade, não existe um feminismo autônomo, desvinculado de uma perspectiva de classe (Saffioti, 1976, p. 131).

Assim, a crítica da autora não se refere apenas ao modo como os feminismos estrangeiros são aplicados à realidade nacional, mas antes se refere à ausência de posicionamento de classe e de horizonte estratégico revolucionário. Aponta a contradição em si de reivindicar a transformação na vida das mulheres sem necessariamente alterar o modo de produção classista e capitalista. No entanto, faz a mediação com a história de nossa formação social, na qual a condição de subalternidade da nos- 
sa economia e a negação de direitos básicos às mulheres, estariam mais preocupadas com o imediatismo da sobrevivência que necessariamente atentas às pautas estritamente políticas ou simbólicas.

Na realidade, as feministas brasileiras não parecem ter se detido nem na análise da realidade econômico-social nacional, nem em um exame aprofundado da ordem social capitalista. Inicialmente, tomando como grupo de referência positiva as feministas européias e, mais imediatamente, as norte-americanas, foram ampliando seus contatos com as conquistas do feminismo em vários países e tentando implantar aqui medidas legais análogas às adotadas em outras nações (Saffioti, 1976, p. 302).

Saffioti conjuga a construção de uma teoria acerca da posição das mulheres na sociedade de classes, a partir da consideração da dimensão estrutural e da dimensão histórica, localizada aos continentes, e países. A sua tese, defendida e amplamente circulada, nunca foi por ela considerada encerrada. Pelo contrário, continuou a elaborar e a tentar se aproximar do entendimento das desigualdades de sexo, raça e classe, sem perder de vista o quanto constituem a formação social brasileira.

Sexismo e racismo são irmãos gêmeos. Na gênese do escravismo constava um tratamento distinto dispensado a homens e a mulheres. Eis porque o racismo, base do escravismo, independentemente das características físicas ou culturais do povo conquistado, nasceu no mesmo momento histórico em que nasceu o sexismo (Saffioti, 2009, p. 25).

Tais preocupações já estavam evidentes em $A$ mulher na sociedade de classes, ao estabelecer como ponto de partida para sua análise da realidade brasileira a formação econômica de nossa sociedade baseada na escravidão moderna, onde "o escravo não apenas se constituía numa mercadoria capaz de mobilizar grandes capitais comerciais, como também se transformava num capital fixo" (Saffioti, 1976, p. 154). Este marco inicial da constituição da estrutura econômica brasileira, como diz Saffioti, ganharia novos contornos em estágios posteriores, sendo fundamental para compre- ender a posição que as mulheres negras ocupam na sociedade brasileira atualmente.

\section{A CONTRIBUIÇÃO DA OBRA DE SAFFIOTI PARA O MOVIMENTO TEÓRICO-POLÍTICO DO FEMINIS- MO NO CONTEXTO BRASILEIRO}

Paralelamente ao feminismo pequeno-burguês e suas reivindicações, a exemplo da indução à "elaboração de uma legislação não reclamada por extensas áreas da população feminina" (Saffioti, 1976, p. 290), aconteciam as lutas dos movimentos femininos de esquerda em torno de "acontecimentos políticos, contra a alta do custo de vida, mas apenas secundariamente em prol dos direitos da mulher" (Ibidem, p. 312). Saffioti continuou escrevendo sobre esse tema ao longo de sua vida. No texto "Feminismos e seus frutos no Brasil" seguiu percorrendo a indagação acerca do "tipo de sociedade capaz de gerar feminismos enquanto movimentos sociais" (Saffioti, 1987, p. 124). A pesquisadora-militante se interessava em desvelar as possibilidades de movimentações feministas que tivessem grande alcance e perdurassem ao ponto de gerar transformações sociais. Questiona-se: "Ainda que as teóricas feministas também desejem construir uma sociedade igualitária do ângulo do gênero (será possível restringir as transformações apenas a este domínio?) (Saffioti, 2009, p. 37). Um de seus argumentos, a nosso ver, trata dessa questão: "Há uma estrutura de poder que unifica as três ordens - de gênero, de raça/etnia e de classe social - embora as análises tendam a separá-las. Aliás o prejuízo científico e político não advêm da separação, para fins analíticos, mas sim da ausência do caminho inverso: a síntese" (Ibidem, p. 26). Ou seja, a questão feminina, no sentido da subalternidade agravada pela sociedade moderna só é possível de ser resolvida ao se pôr fim a este processo de “dominação-exploração” (Saffioti, 2009, p. 30). A conjugação da miséria social ao con- 
texto de repressão militar na década de sessenta fez com que assegurar a sobrevivência tomasse a centralidade de boa parte das preocupações da classe trabalhadora de países latino americanos, e também, no Brasil, tanto no sentido econômico quanto político. Sobre a relação entre os movimentos feministas e os movimentos gerais nesta tensão entre cerco político e resistência, Saffioti se posiciona:

Elas não reagem, a pobreza anula toda e qualquer reivindicação de liberdade; para que a liberdade, se você não tem o que comer? O alimento passa a encher totalmente o horizonte da criatura, ela não pensa noutra coisa, não se coloca o problema da libertação (Saffioti, 1976, apud Singer, 1981, p. 48). ${ }^{1}$

A autora discutiu a influência de quatro perspectivas do feminismo no contexto brasileiro: 1) liberal-burguesa, 2) marxista-dogmática, 3) radical, 4) socialista-feminista (Saffioti, 1987, p. 120) e apenas duas destas tendências tiveram espraiamento na realidade brasileira, a liberal-burguesa e a socialista-feminista, enquanto as outras não produziram movimentações de impacto por parte das mulheres brasileiras. A incorporação da tendência liberal mediante a importação de feminismos estadunidenses e europeus, alcançando entre as suas representantes mulheres letradas e de classes médias brasileiras, não significou que tivemos no Brasil um feminismo hegemônico, como ocorreu nos EUA e Europa. Contudo, expressou o vácuo político entre as reivindicações produzidas pelos setores ligados às camadas ๙ altas e a mobilização das mulheres da classe trabalhadora, pois, o feminismo radical serviu como elemento a dificultar mudanças profundas, conservou o essencialismo feminino, não possibilitou conquistas políticas, nem grande posição, nem chance de vitórias (Saffioti, 1987, p. 113); enquanto o feminismo de inspiração marxista dogmática, devido à apreensão apenas do fenômeno da luta de classes, acabou por negar a concepção materialista, tornando-se reducionista.

1 "A Questão Feminina em Debate" (entrevista), Cadernos do CEAS, $n^{\circ} 42$, março-abril de 1976, Salvador, p. 48.
[...] não obstante as potencialidades altamente significativas do método de análise em que se pretende fundada esta corrente de pensamento, ela apresenta um entrave na conquista de posições estratégicas, conducentes à realização da igualdade social em sua plenitude, posto que, ao permanecer congelada numa leitura novecentista dos clássicos marxistas, nega a dialética materialista, tachando de diversionista o pensamento que avança na captação da globalidade das relações humanas, sem desprezar seus meandros e, portanto, sua tecitura e sua complexidade (Saffioti, 1987, p. 111).

As elaborações teóricas e políticas feministas entre as décadas de 1960 e 1980 tiveram como principal interlocutor a teoria social marxista (Sorj, 1992), seja nos países considerados centrais ou nos periféricos, de modo que o feminismo socialista possibilitou, no que "tange aos feminismos enquanto produção intelectual", situar o Brasil "dentre os países pioneiros" (Saffioti, 1987, p. 124). Aqui também aportaram, pelas mãos das marxistas, as reflexões do feminismo materialista francês que serviu de inspiração a Saffioti, além de Helena Hirata e Elisabeth Souza-Lobo, entre outras. Entre as autoras dessa corrente, destaca-se o diálogo que Saffioti teve com Nicole-Claude Mathieu, em especial com o bastante conhecido artigo "Quando ceder não é consentir" (Mathieu, no prelo). Saffioti o utiliza para rebater o que chama de posições existentes no feminismo que colocam as mulheres agredidas como cúmplices de seus agressores:

Se as mulheres sempre se opuseram à ordem patriarcal de gênero; se o caráter primordial do gênero molda subjetividades; se o gênero se situa aquém da consciência; se as mulheres desfrutam de parcelas irrisórias de poder face às detidas pelos homens; se as mulheres são portadoras de uma consciência de dominadas (Mathieu, 1985); torna-se difícil, se não impossível, pensar estas criaturas como cúmplices de seus agressores. No entanto, esta posição existe no feminismo (Saffioti, 2001, p. 126).

A temática da violência contra a mulher, que acompanhou Saffioti, era, para ela, um objeto que permitia pensar as relações de dominação-exploração. No prefácio de um de 
seus livros, Gênero, patriarcado e violência, ela deixe nítido seu posicionamento militante em busca de respostas:

Se o marxismo clássico atribuía importância excessiva ao macro poder e se os autores que chamaram a atenção para a relevância do micro poder não apresentaram um projeto de transformação na direção da democracia integral, este livro propõe-se a combinar macro e micro processos, a fim de avançar na obtenção deste objetivo. O feminismo aqui esposado traz, em seu bojo, um potencial crítico bastante capaz de apontar caminhos, trilhas, picadas para se atingir o alvo expresso e desejado, ou seja, a democracia plena (Saffioti, 2004, p. 10).

Neste livro também encontramos mais elaborada a imbricação entre as desigualdades de gênero, raça e classe social que estavam presentes desde A mulher na sociedade de classes. Aqui, Saffioti afirma que o nó formado por estas três contradições "apresenta uma qualidade distinta das determinações que o integram. Não se trata de somar racismo + gênero + classe social, mas de perceber a realidade compósita e nova que resulta dessa fusão". Assim,

Uma pessoa não é discriminada por ser mulher, trabalhadora e negra. Efetivamente, uma mulher não é duplamente discriminada, porque, além de mulher, é ainda uma trabalhadora assalariada. Ou, ainda, não é triplamente discriminada. Não se trata de variáveis, mas sim de determinações, de qualidades, que tornam a situação destas mulheres muito mais complexa (Saffioti, 2004, p.115).

Um nó que, para Saffioti, não era apertado, mas sim frouxo. Como analisa Daniele Motta, essa imagem bastante interessante, "pois além de colocar as três relações como estruturantes ainda permite mobilidade entre essas, e mais do que isso, possibilita também que na análise das relações sociais, seja nítida a diferença na desigualdade” (Motta, 2018, p. 7).

\section{ALGUMAS CONSIDERAÇÕES FINAIS}

Ainda no texto Gênero, patriarcado e violência, Saffioti (2004, p. 103) critica a pers- pectiva weberiana de analisar a realidade de forma tripartite - política, econômica e social - por reforçar dualismos típicos da modernidade, na qual o polo negativo estaria sempre relacionado às mulheres. Afirma ainda que boa parte das teorias pós-modernas estão ancoradas nos postulados deste autor, mesmo que não o saibam ou explicitem. Trava um debate no sentido de que o pensamento marxista foi interpelado como sendo sex-blind, mas que, no entanto, "a misoginia de Freud" e sua psicanálise que autorizou a pecha da histeria a comportamentos relacionados a uma suposta descompensação feminina, por exemplo não sofreu esses questionamentos. Contudo, afirma que "como o marxismo não se presta a cumplicidades com o status quo, as críticas a ele dirigidas, no passado e no presente, são superficiais, não atingindo sequer sua epistemologia" (Saffioti, 2004, p. 104).

Em um texto mais próximo ao seu falecimento, intitulado "Filogênese e Ontogênese do Gênero, avança na elaboração em relação à possibilidade da construção de uma teoria feminista que considere as três dimensões ontológicas. "A ontogênese tem-se mostrado uma via adequada para a preservação da unidade do inorgânico, do orgânico e do social" (Saffioti, 2009, p. 15). Afirma que a crítica feminista ao essencialismo biológico, em alguns momentos recaiu em um essencialismo social. "Como, porém, o ser social não poderia existir sem as outras duas esferas ontológicas, não se admite ignorá-las. Mais do que isto, o ser humano consiste na unidade destas três esferas, donde não se pode separar natureza de cultura, corpo de mente, emoção de razão etc.” (Ibidem, p. 35).

Critica as teorias feministas no sentido de não ultrapassarem a gnosiologia, "permanecendo no terreno das categorias meramente lógicas ou epistemológicas" o que não abarcaria a "diversidade do real" (Saffioti, 2009, p. 34) e impossibilitaria a percepção do vínculo orgânico entre gênero e sexo. Afirma que o gênero além de uma categoria histórica é também ontológico no sentido de que todas as sociedades huma- 
nas até agora foram constituídas por relações de gênero, sendo, portanto, constitutivas do ser social, enquanto o patriarcado é um fenômeno histórico, construído e aplicado com o advento da sociedade de classes. Para ela, a recusa em enxergar ou admitir o patriarcado, faz com que as teorias feministas retrocedam, pois "não atacando o coração da engrenagem de exploração-dominação, alimenta-a” (Ibidem, p. 37). Insiste no uso de ambos os conceitos, gênero e patriarcado, inclusive por não serem intercambiáveis. Assim como reforça que o termo relações patriarcais de gênero também se mostra importante, devido ao fato de explicitar o vetor de dominação dos homens sobre as mulheres, atingindo assim o possível caráter de neutralidade da categoria gênero quando utilizada sozinha.

O esforço de Saffioti em levar às últimas consequências a compreensão de fenômenos por ela considerados importantes de serem analisados a faz investigar em profundidade teorias a que ela não está filiada, mas que julga importantes, na construção do objeto pesquisado. Ou seja, a sua opção pelo marxismo e pelo materialismo histórico-dialético faz com que à busca de compreensão da realidade pesquise detalhadamente teorias fundamentadas em outras matrizes, por vezes apenas pela crítica e, em tantas outras pela incorporação crítica de conceitos não necessariamente vinculados à perspectiva de que foi defensora até o final de sua vida. Em muitas partes do seu texto ela సิ afirma, a partir de exemplos, que a constatação ஸे de determinado fenômeno ou ideia não significa uma necessária aderência. Deste modo, a autora legitima a possibilidade de existência i de teorias com as quais discorda, assim como $\therefore$ se permite conhecer em detalhes fenômenos ळ dos quais contesta. "[...] A VIOLÊNCIA AINDA

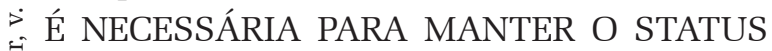
QUO. Isto não significa adesão ao uso da violência, mas uma dolorosa constatação" (Saffioti, 2009, p. 38). Se em 1969, a pesquisadora-militante foi tachada de comunista, a virtude da generosidade com o diferente pareceria certamente escandalosa nos dias obscurantistas a que nos metemos na realidade brasileira, tendo em vista a encalacrada colocada pelas classes dominantes que nos empurram à negação da ciência, da teoria, da história.

No entanto, o exemplo de dedicação ao estudo, ao comprometimento político com as mulheres da classe trabalhadora e, portanto, com toda esta, permite afirmarmos Heleieth Saffioti como uma intelectual orgânica vinculada aos interesses do povo brasileiro que teve fundamental importância no tempo em que viveu e que está imortalizada por sua obra. O seu vasto conhecimento histórico da realidade, a sua própria história de vida e a sagacidade intelectual que lhe é tão própria fez com que tenha se tornado uma das pensadoras da condição das mulheres na formação social brasileira, construído conceitos que em muito contribuíram para compreender fenômenos que estruturam a nossa sociedade, assim como, ousou não separar teoria e política de modo que além da extrema densidade teórica de seus textos, eles são fartos de dados da realidade da época, de temas colocados em evidência na conjuntura, tal como foi o caso da participação das mulheres no mercado de trabalho e nos espaços institucionais da política e da violência contra as mulheres.

Obviamente, sua obra apresenta lacunas, pois apesar da vasta produção intelectual, em uma vida não se consegue abarcar nenhum tema por completo. Insuficiência atestada pela própria autora em seu último texto de maior fôlego “[...] um só intelectual não pode realizar uma tarefa cumulativa, necessariamente de muitos" (Ibidem, p. 23). Mais do que isto: "A construção coletiva de um projeto, mais que a individual, necessita de permanente diálogo, a fim de construir a teoria que orienta a práxis. Melhor dizendo, construir de modo praticamente simultâneo a teoria e a prática não é tão-somente uma obra coletiva, é uma obra para mais de uma geração" (Saffioti, 2009, p. 2) Aceito em 27 de novembro de 2020 


\section{REFERÊNCIAS}

CANDIDO, Antonio. Prefácio. In SAFFIOTI, Heleieth I.B. A mulher na sociedade de classes. Mito e realidade. $2^{\text {a }}$ ed. Petrópolis: Editora Vozes, 1979, p. 9-10.

DAVIS, Angela. Mulheres, raça e classe. São Paulo: Boitempo Editorial, 2016 [1981].

GONÇALVES, Renata. Heleieth Saffioti e a articulação entre teoria marxista e ideias feministas nas Ciências Sociais. Anais do $36^{\circ}$ ENCONTRO ANUAL DA ANPOCS, Águas de Lindóia, 2011.

HARDING, Sandra. Rethinking Standpoint Epistemology: What is Strong Objectivity?. In: KELLER, Evelyn Fox \& LONGINO, Helen E, (eds.), Feminism \& Science, Oxford: Oxford University Press, 1996, p. 235 - 248.

HILL COLLINS, Patrícia. Aprendendo com a outsider Within: a significação sociológica do pensamento feminista negro. Revista Sociedade e Estado - v. 31, n. 1 Janeiro/Abril 2016, p. 99-127.

JUTEAU-LEE, Danièle. Visions partielles, visions partiales: visions des minoritaiers en sociologies. Les femmes dans La sociologie. V. 13, n. 2, outubro de 1981, p. 33-48.

KONDER, Leandro. O futuro da filosofia da práxis. São Paulo: Paz e Terra, 1992 .

MATHIEU, Nicole-Claude. Quando ceder não é consentir. In: MATHIEU, Nicole-Claude. A anatomia política. Salvador: EDUFBA, no prelo.

MÉNDEZ, Natalia Pietra. Entrevista com Heleieth Saffioti. MÉTIS: história \& cultura - v. 9, n. 18, p. 275-294, jul./ dez. 2010.

MOTTA, Daniele Cordeiro. "Desvendando o nó: a imbricação de gênero, raça/etnia e classe na obra de Heleieth Saffioti”. Anais do IX Colóquio Internacional Marx e Engels. Unicamp, 2018.

PINTO, Céli Regina. O feminismo bem comportado de Heleieth Saffioti. Florianópolis Estudos Feministas, 22(1): 321-333, janeiro-abril/2014: pp. 321-333.
POMPEU, Fernanda. Heleieth Saffioti. In: CHARF, Clara (org.). Brasileiras - Guerreiras da Paz. São Paulo: Contexto, 2007, p 67-69.

SAFFIOTI, Heleieth I. B. A mulher na sociedade de classes. Mito e realidade. Petrópolis: Editora Vozes, 1976.

A mulher na sociedade de classes. Mito e realidade. 2 ed. Petrópolis: Editora Vozes, 1979.

Feminismos e seus frutos no Brasil. In: SADER, Emir. (org.) Movimentos sociais na transição democrática. São Paulo: Cortez, 1987.

Contribuições feministas para o estudo da violência de gênero. Cadernos Pagu (16) 2001: p.115-136.

. Gênero, patriarcado e violência. São Paulo: Editora Fundação Perseu Abramo, 2004.

Ontogênese e filogênese do gênero: ordem patriarcal de gênero e a violência masculina contra mulheres. Série Estudos e Ensaios/ Ciências Sociais/ FLACSO - Brasil - junho/2009.

Primórdios do conceito gênero. Cadernos Pagu (12) 1999: p.157-163.

A mulher na sociedade de classes. Mito e realidade. $3^{a}$ ed. São Paulo: Expressão Popular, 2013.

SINGER, Paul. O feminino e o feminismo. In: In: SINGER, Paul \& BRANT, Vinícius (orgs.). O Povo em Movimento. São Paulo: Petrópolis Editora Vozes Ltda. em co-edição com CEBRAP, 1981

SORJ, Bila. O Feminismo na Encruzilhada da Modernidade e Pós-Modernidade. In: COSTA, Albertina \& BRUSCHINI, Cristina (organizadoras). Uma Questão de Gênero. Rio de Janeiro: Rosa dos Tempos; São Paulo: Fundação Carlos Chagas; 1992, p. 16-18.

XAVIER, Libânia. Verbete "Florestan Fernandes". FGV-CPDOC. s/d. Disponível em: <http://www.fgv.br/ cpdoc/acervo/dicionarios/verbete-biografico/fernandesflorestan>. Acesso em: 10/01/2020. 
FEMINIST PRAXIS: Heleieth Saffioti's presence in studies and struggles in Brazil

\author{
Tita Carneiro \\ Maíra Kubík Mano
}

Heleieth Saffioti was an intellectual who, throughout her career, maintained a posture based on feminist praxis: if, on one hand, her theoretical contributions served as inspiration and elucidation for the understanding of inequalities that impact, especially, Brazilian women; on the other hand, feminist and women's movement guidelines were her objects of study and nurtured her work. We can say that Saffioti established, in her production, a symbiotic relationship to the theoretical field in which her work is referenced, to seek syntheses to transform reality. In this article, we reflect on her contributions to feminist studies and struggles in Brazil, revisiting her pioneering book, The Woman in Class Society, at the time of its release and also seeking to understand how her theoretical instrumentality collaborated to analyze and confront social hierarchies.

KeY-words: Academy. Feminist theory. Changing consciousness. Praxis.
PRAXIS FEMINISTE: la présence d'Heleieth Saffioti dans les études et les luttes au Brésil

\author{
Tita Carneiro \\ Maíra Kubík Mano
}

Heleieth Saffioti était une intellectuelle qui, tout au long de sa trajectoire, a maintenu une posture basée sur la pratique féministe: si, d'une part, ses contributions théoriques ont servi d'inspiration et d'élucidation pour comprendre les inégalités qui affectent, en particulier, les femmes Brésiliennes; d'autre part, les agendas féministes et les mouvements de femmes étaient ses objets d'étude et alimentaient son travail. On peut dire que Saffioti a établi, dans sa production, une relation symbiotique typique du champ théorique dans lequel elleappartient et, à travers lui, à rechercher des synthèses pour transformer la réalité. Dans cet article, nous réfléchissons sur ses contributions aux études et aux luttes féministes au Brésil, revisitant son livre pionnier La femme dans la société de classe au moment de son apparitionet cherchant également à comprendre comment ses outils théoriques ont collaboré pour analyser et affronter les hiérarchies sociales.

Mots-CLÉs: Académie. Théorie féministe. Changement de conscience. Praxis. Gênero e Feminismos (NEIM/UFBA). Colunista do Jornal Brasil de Fato Pernambuco e Militante da Marcha Mundial das Mulheres.

Maíra Kubík Mano - Doutora em Ciências Sociais pela Universidade Estadual de Campinas. Docente do Departamento de Estudos de Gênero e Feminismo da Universidade Federal da Bahia e do Programa de Pós-Graduação em Estudos Interdisciplinares sobre a Mulher (PPGNEIM). Pesquisadora do Núcleo de Estudos Interdisciplinares sobre a Mulher (NEIM). Atualmente se dedica a pesquisar os retrocessos em relação aos direitos das mulheres em um contexto de ataque às pautas de gênero e diversidade; e também à representação política e atuação das mulheres eleitas no Parlamento brasileiro. Publicações recentes: Atuar como mulheres - um olhar sobre a política institucional (Curitiba: Appris, 2020); As mulheres desiludidas: de Simone de Beauvoir à ideologia de gênero. Cadernos Pagu, v. 56, p. 1-25, 2019; Fascismo social e pautas feministas: construindo parâmetros para a intensidade da democracia brasileira. In: Danusa Marques; Daniela Rezende; Maíra Kubík Mano; Rayza Sarmento; Viviane Gonçalves Freitas. (Org.). Feminismos em rede. 1ed. 2019, p. 15-28; Direitos reprodutivos: um dos campos de batalha do Golpe. Em co-autoria com Márcia Macedo. In: Linda Rubim; Fernanda Argolo. (Org.). O Golpe na perspectiva de gênero. 1ed.: EDUFBA, 2018, p. 85-103. 